Ambrose, R. y Molina, M. (2010). First-grade Latino English Language Learners' Performance on Story Problems in Spanish versus English. CANADIAN JOURNAL OF SCIENCE, MATHEMATICS AND TECHNOLOGY EDUCATION, 10(4), 356-369,

\title{
First-grade Latino English Language Learners' Performance on Story Problems in Spanish versus English
}

To explore whether teaching English Language Learners (ELLs) with an emphasis on English story problem is appropriate, we compared the performance of a group of Latino first graders when working in Spanish and in English on two equivalent sets of story problems. The students' performance was slightly higher in English than in Spanish, but lower than monolingual students from other studies. ELLs' success in English indicated that the children's knowledge of conversational English was sufficient to comprehend story problems, leading us to conclude that teaching through story problems is a viable approach with ELLs.

Key Words: English Language Learners, story problems, elementary school

Multilingual issues are becoming a relevant topic in mathematics education due to the increasing mobility of the world's population (Barwell, Barton, \& Setati, 2007). Classrooms that in the past might have had monolingual children all speaking the same language now contain students with various language backgrounds. Currently in the United States, the majority of students who do not speak English fluently are Latino, and various American national studies (NAEP, 2007) have shown a notable difference in mathematics achievement between Latino students and their Anglo peers (Gordon, 2004). In many districts across the United States, the most recent trend has been to include English Language Learners (ELLs) in classrooms where English is the dominant language and also the medium of instruction. These students, of very diverse linguistic backgrounds, face the challenge of learning English, in its academic form, at the same time that they have to learn the curriculum (both being mediated by their everyday English language proficiency). However, the danger is that they may learn little mathematics because more attention is being given to their development of fluency in English. Researchbased recommendations provided to policy makers emphasize that ELLs should be provided with rigorous, undiluted curricula coupled with high expectations (Gordon, 2004), but the persistent achievement gap demonstrates that most educators have not figured out how to effectively implement this. Existing research has demonstrated that the lower mathematics achievement evidenced among language minority learners is not solely due to mathematics learning or to language issues (Cocking \& Mestre, 1988), but a complex relationship between both which is, as of now, poorly understood. In our own efforts to promote rigorous curricula for 
ELLs, we have wondered what considerations teachers need to make for ELLs to make the mathematics accessible and maintain high cognitive demands.

\section{Background}

We work with primary school teachers of 5-8 year old children using the principles of Cognitively Guided Instruction (CGI), which focuses on children's strategies for solving story problems as a way to enrich mathematical practices and to promote students' development of mathematical thinking (Carpenter, Fennema, Franke, Levi, \& Empson, 2000). Cited frequently in the research ${ }^{1}$, CGI is lauded for the rigorousness of the instruction in teachers' classrooms (Hiebert \& Grouws, 2007). Among the assumptions underlying the CGI materials is that there are universals that "cut across cultures (Carey, Fennema, Carpenter, \& Franke, 1995, p. 97)" and "children tend to use counting and modelling strategies to solve problems (IBID, p. 97)." These strategies are thought to be intuitive, that is children do not need to be taught them. Research of monolinguals in Spain has replicated Carpenter et al.'s finding for children in middle-income communities (Lago, Rodríguez, \& Caballero, 1999). Adetula's (1989) research of Nigerian children showed that children from different socio-cultural groups developed these intuitions at different rates. As we work with teachers of ELLs we felt the need to know more about the rates at which their students develop these intuitions and whether they were more successful drawing on their intuitions when the problems were presented in their first language.

Research has indicated that children from diverse backgrounds have benefitted from instruction in CGI teachers' classrooms (Tate \& Rousseau, 2007) but these studies did not focus on ELLs. Since CGI is based on research on monolingual English speakers strategies for solving story problems, it is unclear the degree to which this research base generalizes to ELLs working on mathematics in their second language. We chose to compare the results of ELLs with those of the monolingual children in some of the early studies upon which CGI is based (Riley \& Greeno, 1988; Carpenter, Hiebert, \& Moser, 1981; and Carpenter \& Moser, 1981) to insure that the CGI research base generalizes to the population that our teachers work with.

Other researchers have been interested in similar issues. Secada's (1991) study of bilingual (Spanish/English) first graders showed that the children readily solved the simplest problems in both languages but were not as successful as monolingual English speakers on the more complex problem types even though the language complexity was similar. The children in Secada's study were learning mathematics in bilingual classrooms where they did story problems in both languages. He did not hypothesize about why there was a difference in performance between his sample and the monolingual samples in previous research, especially on the Join Change Unknown problem. Nor did he provide data to explore what the children's difficulties might have been. We compared our results to Secada's to see if ELLs in English-only classrooms performed differently than in bilingual classrooms.

${ }^{1}$ Research from the CGI project is cited in 14 of the 31 chapters in Lester (2007). 
Some researchers have found some advantage for bilingual students to solve story problems in their first language (L1) (Adetula, 1990; Bernardo, 1999). These two studies suggest that language issues may significantly affect ELLs' success with story problems administered in their second language (L2), which would need to be taken into account by teachers endeavoring to use the CGI approach in their classrooms. Adetula (1990) and Bernardo's (1999) studies may have limited generalizability because children were being instructed in English but were living in communities where languages other than English were the predominant language, a somewhat different environment from that of the ELLs in North America. The L1 advantage seems to disappear when students are highly competent in both their languages. They tend to outperform monolinguals students as result of having better metalinguistic skills and being more confident in their approach to solving difficult problems (Clarkson, 2006).

\section{Theoretical Perspectives}

Most ELLs persist in having difficulties with academic tasks for several years after achieving proficiency in informal conversation. To explain this phenomenon, Cummins (2000) distinguished between academic language which he characterized as abstract and decontextualized and social everyday language which is concrete and context embedded. Drawing on this theory some mathematics educators argue that the mixture of academic language and everyday language in story problems makes them difficult for ELLs to comprehend. Of particular concern are words that have precise meanings in mathematics but multiple meanings in the everyday world (Kersaint, Thompson, \& Petkova, 2009). Problems written for older students often include academic language, but CGI problems might be more comprehensible to ELLs because they consist primarily of everyday language. With the exception of comparison problems that contain the phrase "how many more does $\mathrm{x}$ have than $y$ ?", academic language that children might only hear in school tends not to appear in the story problems used by CGI teachers. A focus on academic language suggests that problem comprehension of CGI problems should only be an issue for children who have not attained proficiency in everyday conversation and that otherwise children's performance in English and Spanish should be similar to their monolingual peers. Abedi (2004)'s results support this claim. He has collected empirical evidence to show that problems that are worded in accordance with everyday conversation are easier for ELLs to solve. When ELLs were given simplified problem statements that were as short as possible, and avoided passive voice, conditional clauses, subordinate and prepositional clauses and connectors, they were more successful as compared to their success rate when solving problems with the wording typically used on standardized tests.

Making sense of word problems in any language requires students to sift through information indispensible to the problem solution and situational information, including the setting, characters involved, and temporal elements. While the situation information can be helpful to children to understand the relationships in the problem, children have to select which aspects of the problem to attend to and which to ignore (Moreau \& Coquin-Viennot, 2003). Children with 
lower abilities in mathematics tend to have a random selection pattern, often attending to unimportant information that does not contribute to understanding the quantities in the problem and the relationships between those quantities, while higher ability students attend to information that leads to understanding quantitative relationships (IBID). In other words, the more successful students have tuned their selective attention in order to comprehend story problems. Selective attention is one of the benefits of knowing two languages, even when the proficiency in L2 is only partial (Bialystok \& Majumder, 1998). In other words, in general, ELLs have extensive experience tuning out extraneous information to focus on the important elements in conversations and texts. These selective attention skills may or may not be helpful to ELLs as they sift through the information in story problems to understand them.

Many researchers interested in ELLs suggest that it is important to go beyond looking exclusively at the words being used in problems and instead to consider how students might interpret the activity (Moschkovich, 2007). Solving story problems can be considered a discourse practice that children need to be enculturated into. In the case of CGI the practice of solving story problems typically involves children drawing on their intuitive knowledge to solve the problem, including using manipulatives, their fingers or a picture. The children may write numbers on paper but this often happens after solving the problem. A different discourse practice for solving story problems considers solving story problems as an opportunity to apply the formal procedures and algorithms by first writing an equation and then solving it (Koedinger \& Nathan, 2004). Unfortunately for many students this practice can become an activity based on the application of some rules, without any serious consideration of either their related real-world knowledge or the possible constraints imposed by the situation described in the problem (Verschaffel, Greer, \& DeCorte, 2000). Students learn that even when problems are presented as 'realistic', this realism should not be taken too far (Gravemeijer, 1997). In these cases the social norms and mathematical practices in the classroom mislead students to abandon their initial sense-making tendency and to assume some rules for the "game" of solving story problems in school (Verschaffel, et al, 2000). Bernardo and Calleja (2005) found fifth grade bilingual children tended not consider real-world knowledge in problems regardless of whether the language in the problem was L1 or L2. While the CGI research shows that kindergarteners in CGI classrooms tend not to suspend of sense-making (Carpenter, Ansell, Franke, Fennema, \& Weisbeck, 1993), we anticipated that some ELLs may do so when solving story problems, especially if teachers do not make it clear which resources the children are supposed to draw on while engaged in the activity and children assume that they are supposed to apply formally taught procedures.

If ELLs readily engage in the discourse practice of solving story problems using their intuitions, then we would expect that ELLs' performance would depend only on their proficiency in everyday language in L1 and L2. Additionally better performance in L1 could be expected if schooling practices led children to assume a rule-guided approach to solving story problems in English, as it may not necessarily transfer to L1. Suspension of sense-making may have already generalized to L1 in which case performance in L1 and L2 could reflect an application of rules approach. 
We decided to explore the role that the wording of the problem might play for our group of ELLs by varying the complexity of the wording in the problems: keeping some problems as simple as possible and using others problems more representative of the wording found in textbooks.

With these premises and aiming to inform the application of CGI instruction in classrooms with ELLs, we planned the study reported here. Our guiding research questions were as follows:

- What are the differences in the performance of 6 - 7 year old ELLs on story problems in L1 and in L2?

- How do their success rates on various problem types compare to those of monolingual English speakers in previous studies when working in English? In Spanish?

- How do the strategies 6 - 7 year old ELLs use when solving story problems differ in L1 and L2? How do their strategies compare with strategies used by monolingual English speakers when working in English?

\section{Methodology}

We interviewed sixteen 6-to-7 year old Latino ELLs from two schools within the same school district. $80 \%$ of the students in the district received free or reduced lunch, $43 \%$ were designated as ELLs and 35\% of the students were Hispanic. All mathematics instruction was in English. All of the students in the sample had been identified as Spanish speakers at either Early Intermediate or Intermediate (level 2 or 3) levels of English proficiency using the California English Language Development test (California Department of Education, 2010) indicating that they could generate simple sentences in English and had limited English vocabularies. In other words they had some knowledge of everyday conversational English.

While the teachers in our study had been exposed to Cognitively Guided Instruction, the heavy emphasis on performance on the state standardized test led them to adhere closely to their textbook, which did not emphasize a variety of story problems. The teachers also emphasized acquisition of number facts by administering timed tests on a daily basis.

We constructed two equivalent batteries of problems one in English and one in Spanish; both with problems of the same type according to their semantic structure (see Table 1). The problems were also similar in number size and alike in language complexity. The CGI typology of problem types (Carpenter et al., 2000) guided our choice of problem. Using principles laid out by Abedi (2004) the first three problems were linguistically simple: with short sentences, simple and frequent vocabulary, and present or past tenses. We avoided unnecessary linguistic complexity staying away from conditionals, subordinate and prepositional clauses and connectors. The last two problems replicated the wordier problems that students sometimes encounter at school and included more complex linguistic structures.

PLACE TABLE 1 ABOUT HERE 
Both authors interviewed the students in her own L1, one in English and one in Spanish, following Ginsburg's (1997) dynamic assessment model (see Appendix A for the English version of the interview's protocol). The Spanish interview was conducted on one day in a 20 - 30 minute session and the English interview was conducted on another day in a similar timeframe. Each interviewer worked one-onone with a child at the same time the other interviewer was working with another child in a separate area. Blocks, paper and pencil were available to the children. We elicited explanations and coded children's solution strategies. Once we determined what the child could do without any assistance, if the child could not solve a problem or generated an incorrect answer, we supported him/her by rephrasing the problem, suggesting the use of a different or particular tool/resource or asking him/her questions exploring the relationships in the problem (e.g. What does this 7 refer to?, Which are the flowers that your friend has?). We recorded children's success rate on the story problems with and without help. We took field notes and videotaped the interviews, using the videotapes to amplify and correct our notes.

When they successfully solved a problem, children's strategies were coded in one of four categories: a) direct modeling which included occasions when the children used blocks, their fingers or a drawing to represent all of the objects in a problem and acted on those objects in accordance with the action in the story problem; b) counting which included occasions when children used fingers or objects to keep track of their counting activity; c) derived facts were abstract strategies where children reported using number combinations they knew to derive a solution to a problem involving a different number combination ${ }^{2}$, and d) fact strategies were those in which children reported that they recalled the fact associated with the problem. Strategies not fitting any of these categories or strategies that were difficult to interpret were coded as other.

We used the Peabody Picture vocabulary test (PPVT) (Dunn \& Dunn, 1997), a standardized test, to measure students' receptive vocabulary proficiency in English and in Spanish. In this test we gave children a set of four pictures. We said a word, and they chose the picture that best matched it. The words became increasingly less common and when a child began to miss a large percentage of the words, the test ended. To explore children's mathematics language knowledge, we asked them to do some counting tasks in both languages: counting from 10 to 25 and saying the numbers that come after 49, 89, 99, 200 and 999.

\section{Findings}

In this section we first present the results of this study and later compare them to those of other studies on monolingual and bilingual students' performance on similar story problems.

\section{Students' language proficiency}

Results of the PPVT indicated that the students' receptive vocabulary ranged from an age equivalent of 3 years -6 months to 7 years- 3 months in English, and 2

${ }^{2}$ For example, to solve a problem involving $7+8$, the child might use the fact $7+7=$ 14 and then add 1. 
years-11 months to 6 years- 6 months in Spanish (see Table 2). The average of the results of the test of all the students was slightly higher in English than in Spanish: an age equivalent of 4 years- 11 months versus 4 years -9 months. Seven students performed higher or slightly higher in Spanish and one performed similarly in both languages. The other eight children did better in English. In addition, only 5 of the 16 students were able to count from 10 to 25 in Spanish. In the Spanish interview, in most problems students needed to count in English in order not to miscount and to hear the numbers of the problems in English to be able to correctly identify them. All of the children were fluent in the number sequence to 100 in English.

PLACE TABLE 2 ABOUT HERE

Performance in each language

PLACE TABLE 3 ABOUT HERE

Table 3 shows children's success rates, without interviewer support, on each of the problem types. About $70 \%$ of the children were successful solving both versions of the Separate Result Unknown problem and the Wordy Part-part-whole whole unknown problem in both languages. The wordiness of the last two problems of the set did not negatively affect the students' performance. Students encountered some difficulties in the Join Change Unknown and Compare Difference Unknown problems. To further inspect these difficulties we examined children's performance on those problems without and with interviewers' help. When given some additional support to reconsider their initial answers and to relate the quantities in their work back to the quantities in the problem, more children successfully solved the problem bringing the success rates to 56\% (English) and 44\% (Spanish) in the Join Change Unknown problem. For example, after providing an incorrect answer, J heard the problem reformulated which was enough to help her solve it correctly:

J: (after initially hearing the Join Change Unknown problem) Twelve? No,... twelve.

I: Ok, can you tell me how you figured that out?

J: Ummm because... she had... six, six books, and... she got twelve more books. So it's twelve.

I: Let me read you the problem again. The teacher had six books. And then she got some new ones. And now she has twelve books in all. How many new books did she get?

J: (she counts on her fingers from 6 to 12) Six.

I: How did you get six?

$\mathrm{J}$ : Because there was six, plus six, twelve.

In contrast to the improved performance on the Join Change Unknown problem, even with support children continued to be unsuccessful on the Compare Difference Unknown problems. Reformulating the problem or relating the student actions and the numbers described in the problem, was not effective to help them solve this type of problem in either language. The following is an example from A's 
English interview. He asked to hear the problem twice. After building a row of sixteen red blocks he asked the interviewer for the numbers in the problem. Then he built another row with ten blue blocks, placed both rows together and counted all the blocks giving 26 as answer:

A: I counted the sixteen all together, and I put the... I put the ten together and it makes twenty-six.

I: So who has more flowers? Do you have more flowers or does your friend have more flowers?

A: I have more flowers.

I: You have more flowers. How many more flowers do you have?

A: Twenty-six

I: Do you have twenty-six more than your friend?

A: He nods.

Despite the interviewer's query about its reasonableness, A confirmed his answer.

\section{Comparison with other studies}

Results for children in our study were similar to results from other studies with similar problems (see Table 4) ${ }^{3}$. Like the children in Secada (1991)'s study, the children in our study performed similarly in English and in Spanish with a slightly higher success rate in English. In the case of the Join Change Unknown and Compare Difference Unknown problems, the success rates were similar in both studies while performance on the Separate Result Unknown was higher in our study.

\section{PLACE TABLE 4 ABOUT HERE}

Children in our study as well as in Secada (1991)'s slightly underperformed children in Riley and Greeno's (1988) study on the Join Change Unknown problems. When help was provided on the Join Change Unknown problem, children's success rate was similar to that in the Riley and Greeno's study. Success rates across all three studies were low on the Compare Difference Unknown problems.

As Riley and Green (1988) did not provide specific information about the strategies used by the students in their study, we looked at Carpenter and Moser (1981) and Carpenter et al. (1981)'s results to contrast the type of strategies used by our students to those of monolinguals (see Table 5). Direct modeling was the most common strategy used by children across all studies. Our students used number facts more often than children in the other two studies and some of the strategies used by children in the other two studies did not fall into the categories: direct modeling, counting, derived fact, or fact.

PLACE TABLE 5 ABOUT HERE

3 Even though our sample was just of 16 students, we express the results in percentages to compare them with those of other studies. 


\section{Discussion}

In this section we discuss the findings above. We first focus on comparing students' performance in English and Spanish, and then we comment on the comparison between monolingual, bilingual and ELL students' success rates and strategy use.

\section{Language proficiency and performance in each language}

The children's performance on the PPVT indicated that 13 of the children had some linguistic comprehension abilities in both English and Spanish (i.e. they had at least 4-02 receptive vocabulary age-equivalent). It was clear from our informal conversations with the students that they had extensive exposure to both languages. While their mastery of vocabulary in each language lagged a bit behind their monolingual peers, we found their competence in the two languages to be impressive. Although most seemed enthusiastic about the prospect of doing some mathematics in Spanish, during the Spanish interview many expressed a preference for doing mathematics in English by claiming that solving story problems was harder in Spanish and by counting and naming the numbers in English. Some of them told us that in their homes they do math with siblings in English.

We found it notable that many of the children could not count well in Spanish even when their Spanish vocabularies were otherwise typical of children their age. This may be the reason for their slightly better performance in English. We believe that learning to count in Spanish would be advantageous for these students. According to Cummins (2000) and Clarkson (2006), high levels of proficiency in L1 and L2 has cognitive advantages and knowing the number words in Spanish would contribute to the children's overall L1 proficiency. Moreover it would enable them to comprehend and participate in mathematical activities in Spanish-speaking contexts, which would contribute to their overall mathematics learning and continue their development of mathematical intuitions in informal settings.

Considering that these students do not have formal mathematics experience in Spanish, their slightly better performance in English could also be a result of their lack of practice in using selective attention in mathematics situations described in their first language. As their use of Spanish is more related to social communication, their attention may have been more focused on the context of the story in the problem rather than on the mathematical relations and numbers in it. Unlike Adetula (1990) and Bernardo (1999) we did not find an advantage for our ELL students to solve story problems in their first language. Since the children in our study performed similarly in English and in Spanish we concluded that children were fluent enough in everyday language in each language to solve problems. The wordy problems did not pose a challenge to the children in either language; so excessive care in making problems as short and linguistically simple as possible is not warranted when children have command of everyday language. We do not dismiss the importance of attending to Cummins' (2000) distinction between academic and everyday language, but note that the children in our sample could make sense of problems with longer sentences, less common words and some prepositional phrases. 


\section{Strategies used}

Considering that knowledge of the strategies used by students when solving problems (together with how they evolve) is a main component of CGI teaching and professional development, we attended to the type of strategies used by the students when working in each language. As we previously showed, similar frequency was detected in the strategies used in both languages. Direct modeling strategies were the most frequent, followed (in this order) by the use of recalled facts, counting and derived facts. Therefore the language in which the problem was stated did not limit students' access to their informal knowledge and natural cognitive powers. Students used their intuitive strategies when working in both languages even if some of them had to count and name the numbers in English in the Spanish interview. These results suggest that the students' informal mathematical experience, either in L1 or L2, transferred to the other language and that the students' understanding of English was enough to access their intuitions.

\section{Comparison with monolingual's students}

Like monolingual students, the students in our study were most successful on problems where the result was unknown and encountered the most difficulties in the Compare Difference Unknown problem. However, our ELL students slightly underperformed Riley and Greeno's (1988) monolingual students on the Join Change Unknown problems. Several children's first response in this problem was to add the quantities or give one of the numbers as an answer, suggesting that they attended to the joining action and/or the numbers in the problems but not to the other specifics. J's work above illustrates this phenomenon. When we repeated the problem and encouraged children to try again on the Join Change Unknown problem, the children's success rates were similar to those of monolinguals. Considering that "control of attention is possibly a general outcome of bilingualism (Bialystok \& Majumder, p. 71)," we posit that the ELLs in our study may have been overly selective in their attention, and not have attended to enough of the features in the Join Change Unknown Problem. In the case of our English Join Change Unknown problem, it doesn't matter that the objects in the problem are books or that the person in the problem is a teacher. Children could successfully solve the problem without remembering these details. On the other hand, they must remember that there was an initial set of 6 and an ending set of 12, and that the action in the problem involves joining. Since the Join Change Unknown problem is more complex than the Separate Result Unknown problem, students have more features to attend to and selective attention issues may play a greater role in this problem type than others.

The slight underperformance evidenced by our students in the Spanish Separate Result Unknown problem seems mainly a result of their limited fluency counting and naming the numbers in Spanish. Counting backwards was a strategy only used in this type of problem which led two students to miscount. Another two students' wrong answers were due to confusing the numbers in the problem. So the special difficulties encountered in this problem were not in understanding the 
quantitative relations described in the problem as students used a correct strategy but had trouble recognizing the numbers and counting backwards in Spanish.

The Compare Difference Unknown problem remained difficult in both languages for the children even with interviewer support. This problem type is among the more difficult for children to solve (Carpenter, et al. 1993,). Children rarely quantify comparisons in their everyday lives so they do not have the same wealth of experience to draw on as they do for joining and separating problems. In addition, comparison problems involve static situations which do not indicate a joining or separating action. As noted earlier, the question, "how many more does X have than Y?" contains academic language not often heard outside of school in either L1 or L2. But even when we avoided this language saying instead, "how many extras does X have?" children were still unable to solve the problem. This is in keeping with Davis-Dorsey, Ross and Morrison's (1991) finding in which rewording the question in a Comparison Difference Unknown problem did not increase second grader's success rate. This problem type illustrates how the wording of the problem makes it difficult, as does the mathematical structure.

The ELLs in our study used number facts more often than the monolingual children in the comparison studies. This data, coupled with our observations of the students, suggested that some of the children might have interpreted the interview as an opportunity to apply formally taught procedures rather than use their intuitions (Koendinger \& Nathan, 2004). As in the examples of A's work on the Compare Difference Unknown problem, some children's first reaction to problems was to consider adding the numbers they heard. In J's case (and several of her peers) a reminder to listen more closely to the problem was all that was required to get her to draw on her intuitions. We offer this explanation tentatively and in future work intend to look more closely at the data with this issue in mind.

\section{Conclusion}

Taken as a whole the findings support the use of CGI with Spanish speaking ELLs in English-Only classrooms. The ELL's knowledge of English was sufficient to draw on their intuitions. The fact that our students performed similarly in both Spanish and English suggests that the syntax and vocabulary of the problems in English were not a source of difficulty. Among the adaptations that might benefit ELLs when working on story problems is for teachers to help children become aware of their use of selective attention so that it becomes an asset to their work on story problems.

The results on student's use of strategies support the research base on students' development of mathematics thinking in which CGI teaching and professional development is based, independently of either L1 or L2 being the language of students' informal mathematics experience.

Along with other researchers investigating the interplay between language and mathematics we believe that learning mathematical discourse should be emphasized for all students, especially for ELL students. This includes using word problems as an important part of mathematics instruction. In addition, extensive experiences with the more complex problems types situated in meaningful contexts 
in their classrooms may help ELLs to tune their selective attention to the mathematical structures involved and overcome the superficial thinking related to the "game of word problems" that can plague all children. Since solving story problems is a central discourse practice in mathematics classroom, ELLs would benefit from teachers making it clear what the role of intuitions, tools and formal procedures are in this situation so that students can take full advantage of the resources at their disposal.

\section{References}

Abedi, J. (2004). No child left behind act and English Language learners: Assessment and accountability issues. Educational Researcher, 33(1), 4-14.

Adetula, L. O. (1989). Solutions of simple word problems by Nigerian children: Language and schooling factors. Journal for Research in Mathematics Education, 20(5), 489-497.

Adetula, L. O. (1990). Language factor: does it affect children's performance on word problems. Educational Studies in Mathematics, 21, 351-365.

Barwell, R., Barton, B., \& Setati, M. (2007). Multilingual issues in mathematics education: introduction. Educational Studies in Mathematics, 64(2), 113-119.

Bernardo, A. B. I. (1999). Overcoming Obstacles to Understanding and Solving Word Problems in Mathematics. Educational Psychology, 19(2), 149-163.

Bernardo, A. B. I., \& Calleja, M. O. (2005). The effects of stating problems in bilingual students' first and second languages on solving mathematics word problems. The Journal of Genetic Psychology, 166, 117-128.

Bialystok, E., \& Majumder, S. (1998). The relationship between bilingualism and the development of cognitive processes in problem solving. Applied Psycholinguistics 19, 69-85.

California Department of Education (2010). CELDT Test Interpretation Guide. Retrieved from http://www.celdt.org/resources/im/ on May 12, 2010.

Carey, D., Fennema, E., Carpenter, T., \& Franke, M. (1995). Equity and mathematics education. In W. Secada, E. Fennema, \& L. Adajian (Eds.), New Directions for Equity in Mathematics Education (pp. 93-125). New York: Cambridge University Press.

Carpenter, T. P., Ansell, E., Franke, M. L., Fennema, E., \& Weisbeck, L. (1993). Models of problem solving: A study of kindergarten children's problem-solving processes. Journal for Research in Mathematics Education, 24(5), 428-441.

Carpenter, T. P., Fennema, E., Franke, M., Levi, L., \& Empson, S. B. (1999). Children's mathematics: Cognitively Guided Instruction. Heinemann: Portsmouth, NH.

Carpenter, T.P., Hiebert, J., \& Moser, J. (1981). Problem structure and first-grade children's initial solution processes for simple addition and subtraction problems. Journal for Research in Mathematics Education, 12(1), 27-39. 
Clarkson, P. C. (2006). Australian Vietnamese students learning mathematics: High ability bilinguals and their use of their language. Educational Studies in Mathematics, 64(2), 191-215.

Cocking, R., \& Mestre, J. (1988). Linguistic and cultural influences on learning mathematics. Hillsdale, NJ: Erlbaum.

Cummins, J. (2000). Language, power and pedagogy. Clevedon: Multilingual Matters.

Davis-Dorsey, J., Ross, S. M., \& Morrison, G. R. (1991). The role of rewording and context personalization in the solving of mathematical word problems. Journal of Educational Psychology, 83(1), 61-68.

Dunn, L. M. \& Dunn, L. M. (1997). Peabody Picture Vocabulary Test (3rd ed.). Circle Pines, MN: American Guidance Service.

Gravemeijer, K. (1997). Commentary solving word problems: A case of modeling. Learning and Instruction, 7, 389-397

Ginsburg, H. P. (1997). Entering the child's mind: The Clinical Interview In Psychological Research and Practice. Cambridge: Cambridge University Press.

Gordon, E. (2004). Closing the gap: High achievement for students of color. Research Points: Linking Research to Education Policy. Washington, DC: American Educational Research Association.

Hiebert, J., \& Grouws, D. (2007). The effects of mathematics teaching on student learning. In F. Lester (Ed.), Second handbook of research on mathematics teaching and learning (pp 371 - 404). Reston, VA: National Council of Teachers of Mathematics

Kersaint, G., Thompson, D. R., \& Petkova, M. (2009). Teaching mathematics to English language learners. Routledge: New York, New York.

Koendinger, K. \& Nathan, M. (2004). The real story behind story problems: Effects of representations on quantitative reasoning. Journal of Learning Science, 13(2), 129-164.

Lago, M. O., Rodríguez, P., \& Caballero, S. (1999). La resolución de problemas verbales de multiplicación y división en niños de educación infantil. Comunicación presentada en el III Congreso Internacional de Psicología y Educación, Santiago de Compostela, Spain, 8- 11 September $1999 .$.

Lester, F. K. (2007). Second handbook for research in mathematics teaching and learning. Information Age Publishing: Charlotte, NC.

Moreau, S., \& Coquin-Viennot, (2003). Comprehension of arithmetic word problems by fifth grade pupils: Representation and selection of information. British Journal of Educational Psychology, 73, 109-121.

Moschkovich, J. (2007). Bilingual mathematics learners: How views of language, bilingual learners and mathematical communication affect instruction. In N. S. Nassir \& P. Cobb (Eds). Improving access to mathematics (pp. 89 -104). New York: Teachers College Press. 
National Assessment of Educational Progress (NAEP) (2007). National Center for Education Statistics [NCES]. http://nces.ed.gov

Riley, M. S., \& Greeno, J. G. (1988). Developmental analysis of understanding language about quantities and of solving problems. Cognition and Instruction, 5, 49- 101.

Secada, W. G. (1991). Degree of Bilingualism and arithmetic problem solving in Hispanic first graders. The Elementary School Journal, 92(2), 213-231.

Tate, W. F., \& Rousseau, C. (2007). Engineering change in mathematics education: Research, policy and practice. In F. Lester (Ed.), Second handbook for research in mathematics teaching and learning. Information Age Publishing: Charlotte, NC.

Verschaffel, L., Greer, B., \& DeCorte, E. (2000). Making sense of word problems. Lisse, The Netherlands: Swets y Zeitlinger. 